Background and Aims Preterm infants need effective pain management during and after the frequent painful procedures that guarantee their survival, whereas insufficient pain control may have negative impact on development of cognition, motor function and behaviour in preterm infants. The aim of this study was to assess the analgesic effect of lullaby music on pain score during venipuncture in preterm infants.

Methods 60 healthy preterm infants with a gestational age of 32-36 weeks randomly assigned to two groups in a double blind manner (30 in each group). For infants in experimental group lullaby music, with 40-50 db, was played 2 min before venipuncture. In control group, infants did not receive any intervention. For two groups, Two video systems were used to videotape the infant's face and monitor during study. pain scores were calculated by using Premature Infant Pain Profile (PIPP) before intervention, during the 30 sec after needle insertion, $30 \mathrm{sec}$ after removal needle and $10^{\text {th }} \mathrm{min}$ after the end of venipuncture.

Results During the $30 \mathrm{sec}$ after needle insertion, there was no significant decrease in pain score in experimental group to compare with control group ( $p=0.075)$ whereas $30 \mathrm{sec}$ after the end of venipuncture, reduction in pain score was observed in experimental group ( $\mathrm{p}=0.0001)$.

Conclusion In lullaby music group, reduction in pain score during venipuncure did not observe, but Immediately after the end of procedure, significantly pain score decreased. So duration of playing music can be affected on pain responses during venipuncture in preterm infants.

\section{THE EFFECTS OF CLOWN INTERVENTION ON FATIGUE IN CHILDREN WITH CANCER UNDERGOING CHEMOTHERAPY}

doi:10.1136/archdischild-2012-302724.1904

${ }^{1} \mathrm{~F}$ Petrangeli, ${ }^{1} \mathrm{~A}$ Sili, ${ }^{1} \mathrm{~F}$ D'Agostino, ${ }^{2} \mathrm{~T}$ Petrangeli, 'N Cittadini, 'E Antonacci, ${ }^{1} \mathrm{R}$ Alvaro. 'School of Nursing, University 'Tor Vergata' ${ }^{2}$ Department of Pediatric Hematology and Oncology, Bambino Gesù Children's Hospital, IRCCS, Rome, Italy

Background and Aims Many studies show that cancer-related fatigue is one of the most common symptoms experienced by children as a side effect of cancer therapy. This problem has recently grown considerably. Nurses envolve in assisting children and parents to face illness and treatment procedures. The aim of this study was to investigate whether clown intervention could reduce fatigue in children with cancer undergoing chemotherapy.

Methods Ninety-nine children (aged 7-18 years) with cancer and with at least one cycle of chemotherapy, and one of their parents, participated in the study:during their hospitalization 54 of them interacted with clowns in the ward, while 45 children did not get them. Fatigue as measured by PedsOL Multidimensional Fatigue Scale and structured cognitive interviews on clown therapy.

Results The results emphasized the relevance of clown intervention on the reduction of fatigue in children. The study shows that in the sample that received clown intervention, the fatigue score was better than appears in the sample without the support of this activity (77.4DS $\pm 13.9 v s 49.3 \mathrm{DS} \pm 9.9 \mathrm{p}=.000)$, and that cognitive fatigue domain had the least affected (90vs62), compared with general fatigue (73.4DS $\pm 16.9 \mathrm{vs} 49.2 \mathrm{DS} \pm 12.4$ ) and sleep fatigue (69DS $\pm 16.4 \mathrm{vs} 37.3 \mathrm{DS} \pm 11.5)$ domains. Age was a factor associated with a significant increase in the fatigue scores.

Conclusions Children that receive the clown's care has shown a lower fatigue. It is essential for healthcare professionals to consider the effect of chemotherapy on the children and to recognize the specific needs of this patient. Nurses should routinely screen pediatric patients for fatigue and intervene to minimize their impact using pharmacologic and nonpharmacologic strategies.
1905 “KEEPING THE FAMILY TOGETHER" VERSUS “THE WORST
JOURNEY OF OUR LIVES”: PARENTS TRAVELLING WITH
REGIONAL PAEDIATRIC INTENSIVE CARE TRANSPORT
TEAM

doi:10.1136/archdischild-2012-302724.1905

SL Barlow, K Claydon-Smith, S Santo, E Waltho, K Parkins. NWTS, Warrington, UK

Background From approximately 1.7 million children North West and North Wales (UK), 600-700 transferred annually from 31 hospitals into 2 regional PICs. PICS standards 2010 state "wherever possible and appropriate, parents should be given the option to accompany their child during transfer". Parental stress is increased by not being able to travel with their child (1). Pre-NWTS, unitbased PIC transport teams use of front-line ambulances precluded parents travelling with their child. North West and North Wales PIC Transport Service (NWTS) started November 2010, as single dedicated regional service. Our service level agreement with private ambulance provider states must have four seats to ensure minimum one parent can travel

Methods Prospective audit of NWTS database (first year). NWTS staff questionnaire.

Results 558 parents (100\%) offered opportunity to travel with their child, 328 accepted (58.8\%).

\section{Abstract 1905 Table 1}

\begin{tabular}{lllll}
\hline 1 Parent & 2 Parents & No Parents & Data missing & Team vetoed \\
\hline 287 & 41 & 123 & 56 & 4 \\
$51 \%$ & $7 \%$ & $22 \%$ & $10 \%$ & $1 \%$ \\
\hline
\end{tabular}

Pre-NWTS, staff voiced concerns particularly potential difficulties if child deteriorated during transfer with parents present. Post NWTS, majority of staff recognise positive benefits especially if child may not survive, and no adverse incidents reported relating to parents.

Conclusion Parental uptake of an opportunity to travel with their child is a ringing endorsement of our new policy. "NWTS not only kept our daughter alive, but kept our family together."

References 1 "The worst journey of our lives": parents' experiences of a specialised paediatric retrieval service. Intensive Crit Care Nurs. 2003 19(2):103-8 Colville G et al.

\section{ALL ABOARD: THE USE OF SIMULATION FOR EDUCATING THE MULTIDISCPLINARY RETRIEVAL TEAM WITHIN THE SOUTH THAMES RETRIEVAL SERVICE}

doi:10.1136/archdischild-2012-302724.1906

F Bickell, K McCulloch. PICU, Guy's \& St Thomas' NHS Foundation Trust, London, UK

Background This presentation will explore the evolution of retrieval team training from the inception of the service in 1998 to the present day.

Just as the service has expanded from its very early days when teams took plastic bags of potentially useful kit out in a taxi to the local hospitals so the training of teams has developed to ensure team members are as ready as possible for the varied experiences they may encounter when out on the road.

Method Recently we have introduced multidisciplinary simulation training where nurses, doctors and ambulance technicians are brought together and are exposed to realistic retrieval scenarios based upon real situations that teams have already encountered.

Although clinical issues are discussed during debriefing the team are also encouraged to explore the 'human factors' in each scenario and examine how they have influenced, both the outcome and dynamics of a situation, (Sherwood et al 2002). 